\title{
Emission and Transmission Gamma-ray Computed Tomography
}

\author{
Tzu-Fang Wang
}

December 1996

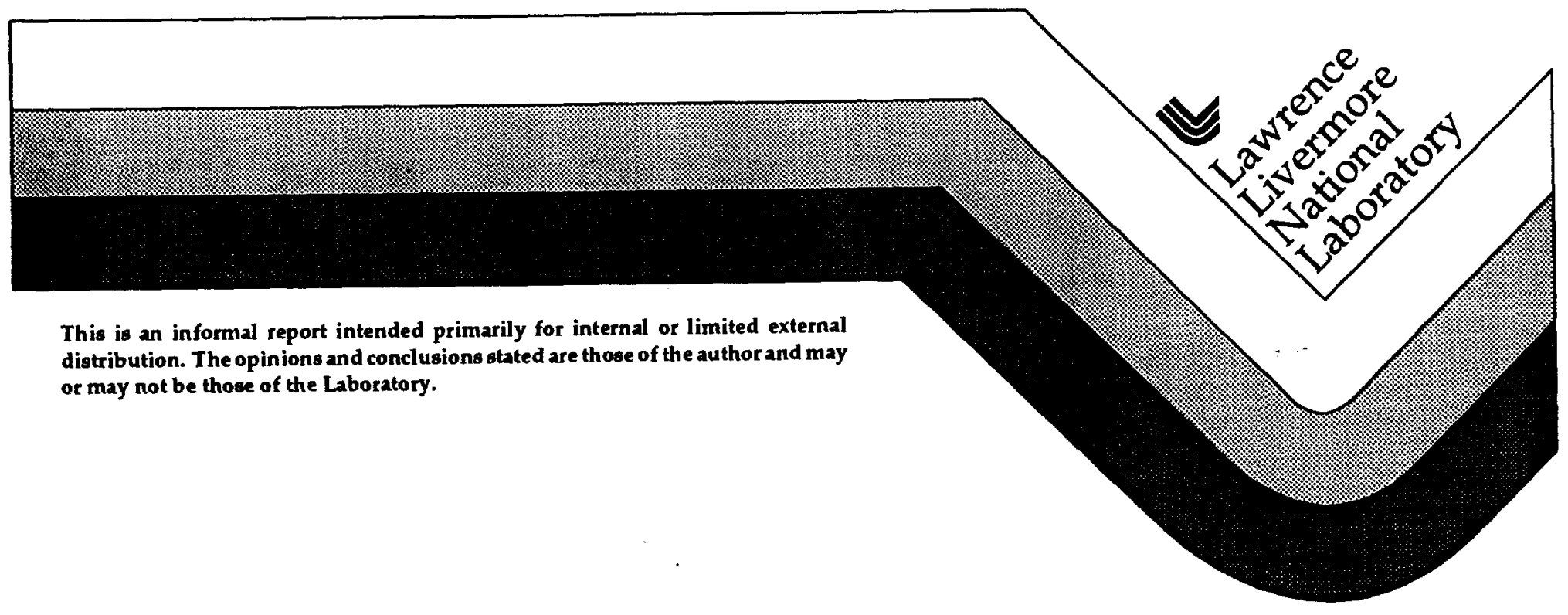




\section{DISCLAIMER}

This document was prepared as an account of work sponsored by an agency of the United States Government. Neither the United States Government nor the University of Calfornia nor any of their employees, makes any warranty, express or implied, or assumes any legal liabilty or responsibility for the accuracy, completeness, or usefulness of any information, apparatus, product, or process disclosed, or represents that its use would not infringe privately owned rights. Reference hereln to any specific commercial products, process, ar service by trade name, trademark, manufacture, or otherwise, does not necessarily constitute or imply its endorsement, recommendation, or favoriag by the United Stales Government or the University of California. The views and opinions of authors expressed herein do not necessarily state or reflect those of the United States Government or the University of California, and shall not be used for advertising or product endorsement purposes.

This report has been reproduced

directly from the best available copy.

Available to DOE and DOE contractors from the Omice of Scientific and Technical Information

P.O. Box 62, Oak Ridge, TN 37831

Prices available from (615) 576-8401, FTS 626-8401

Available to the public from the

National Technical Information Service

US. Department of Commerce

5285 Port Royal Rd.

Springfield, VA 22161 


\title{
Emission and Transmission Gamma-ray Computed Tomography
}

\author{
Tzu-Fang Wang \\ Lawrence Livermore National Laboratory \\ Livermore, CA 94550
}

We are adapting emission and transmission computed tomography (E\&T CT) of gamma rays for the nondestructive analysis of the special nuclear materials (SNM) uranium and plutonium in small, dense heterogeneous samples of the type stored throughout the Department of Energy complex. The computed tomography method employing transmission of gamma-rays has been widely used in medical applications for diagnostic purposes. We are extending this method by also utilizing the gamma rays emitted by the sample itself to measure a three-dimensional distribution of SNM, and to quantify it in heterogeneous samples such as plutonium buttons from the molten-salt extraction (MSE) process.

In the conventional gamma-ray detection method commonly used for the nondestructive assay of SNM, the energies and intensities of gamma rays emitted from the sample are recorded with a simple detection system. The content of SNM in the sample is then derived from the properties of the characteristic gamma rays. This technique relies on the important assumption that the material in sample is homogenous throughout, and therefore gamma rays are attenuated uniformly.

In many of cases, this technique can not quantitatively assay SNM due to the heterogeneous nature of the sample. For example, it is extremely difficult to accurately correct for gamma-ray attenuation within a sample when the uranium or plutonium in it occurs in lumps and/or when the sample matrix itself varies in composition or density.

On the other hand, transmission CT, using external radioactive sources, maps out the density distribution of the sample, while emission CT, using characteristic gamma rays of the SNM, maps out the location of SNM in the sample. By combining results from both we can perform a gamma-ray attenuation correction through the sample so that quantitative determination of SNM in a MSE plutonium button, or similar sample, can be obtained.

Figure. 1 shows a photograph of our CT scanner. A precision stage allows accurate translation and rotation of the sample mounted on it. During emission CT, gamma rays emitted by the sample are collimated by a small high-precision lead collimator onto a germanium detector. A three-dimensional scan of the entire sample is obtained by controlled movement of the stage. During transmission CT, the gamma rays from an external source are shown onto the sample, and after traversing the sample and the collimator, impinge on the detector. Movement of the sample stage again allows a full scan of the sample. 
We have concentrated on the assay of MSE plutonium buttons during the development of the tomography method, since they are representative of a large number of existing heterogeneous SMN samples. In the MSE process, plutonium present in the remnants from a variety of processes is recovered by extraction with a molten salt. Quantitative determination of plutonium in the resulting buttons using conventional gamma-ray detection has been uncertain since the results have depended on an approximate model that describes the distribution of the plutonium, the daughter americium, and salt residue within the button in order to determine the attenuation.

In the CT approach, the effect of a non-uniform distribution is measured directly, thus eliminating the need for a model. Figure. 2 shows three two-dimensional slices of transmission tomographic image of a MSE plutonium button which reveals heterogeneities within the sample that are difficult to detect and quantify by other methods. When combined with the emission tomographic data, we can obtain the distribution of plutonium and americium.

The tomographic method we are developing can be applied to a wide variety of heterogeneous SNM samples. The assay of these samples for material control and accountability purposes can be improved throughout the DOE complex by application of emission and transmission computed tomography.

This work was performed under the auspices of the U.S. DOE by the LLNL under Contract No. W-7405-ENG-48. Work was supported by the Office of Safeguards and Security.

\section{Figure Captions:}

Figure 1. A photograph of our scanner system.

Figure 2. Three two-dimensional slices of tomographic image of a MSE button. 


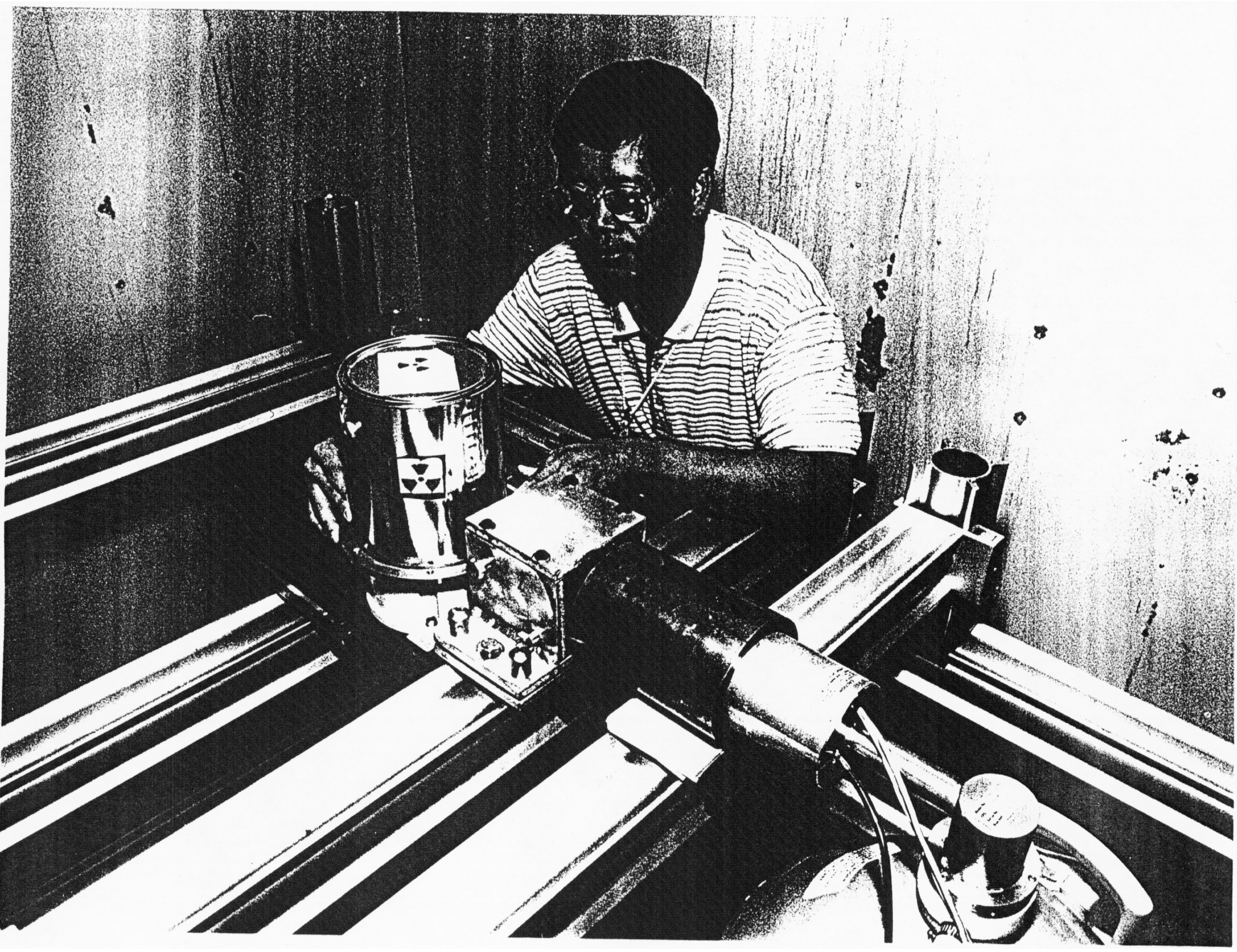




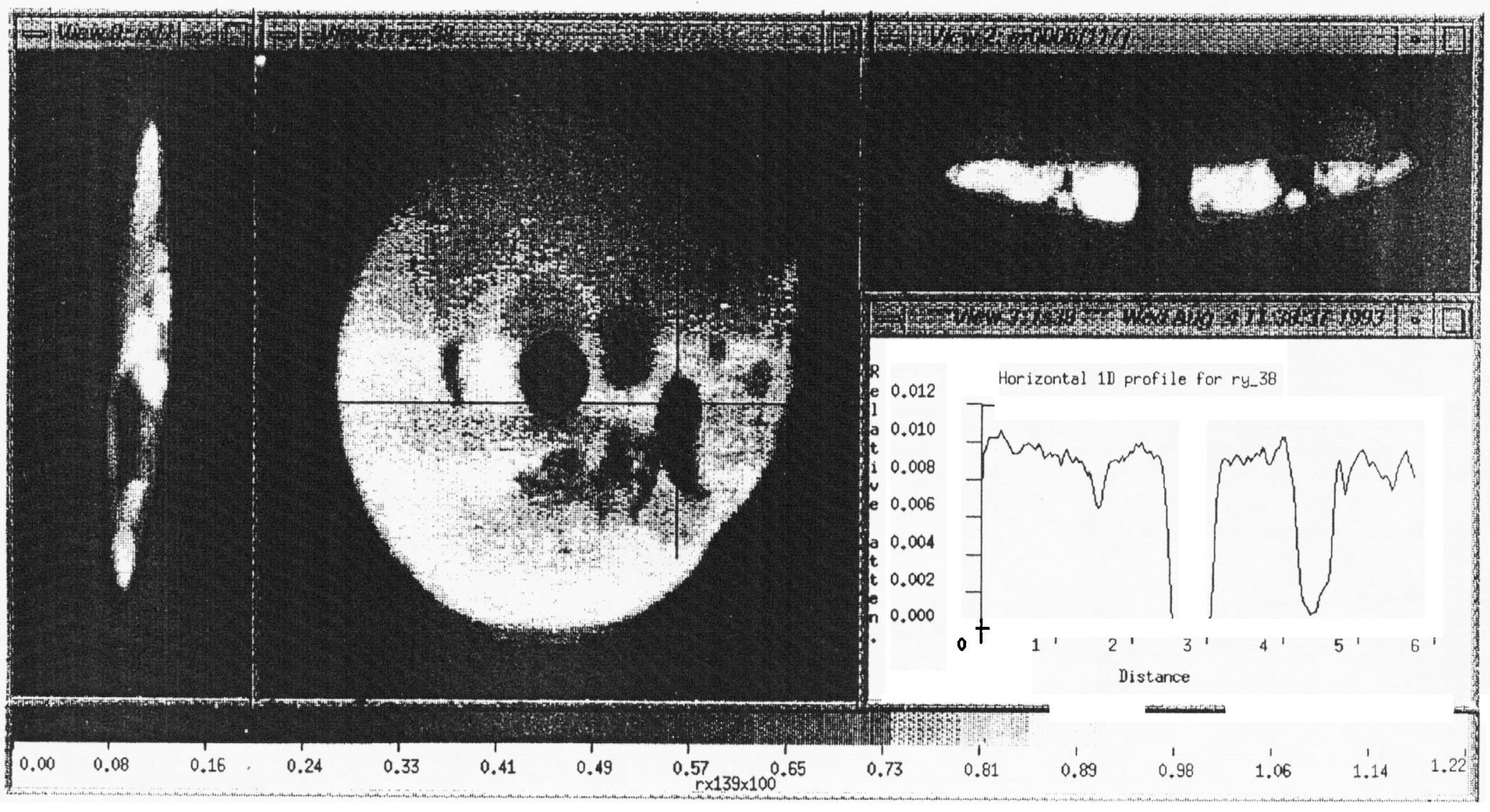




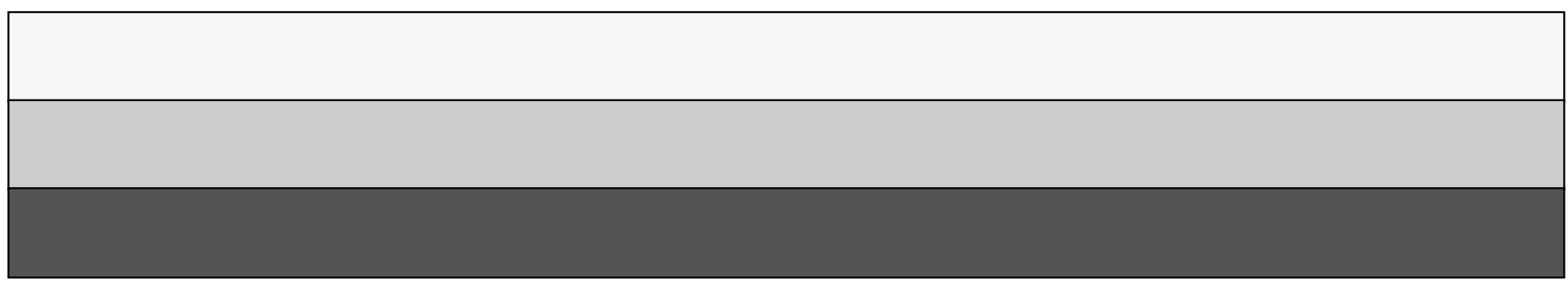

